\title{
Angiographic outcomes of radial artery versus saphenous vein in coronary artery bypass graft surgery: A meta-analysis of randomized controlled trials
}

\author{
Christopher Cao, MBBS, BSc(Med), ${ }^{\text {a,b,c }}$ Con Manganas, MBBS, ${ }^{\mathrm{c}}$ Matthew Horton, MBBS, ${ }^{\mathrm{c}}$ \\ Paul Bannon, MBBS, PhD, ${ }^{\mathrm{a}, \mathrm{b}}$ Stine Munkholm-Larsen, MD, ${ }^{\mathrm{a}, \mathrm{d}}$ Su C. Ang, MBBS, ${ }^{\mathrm{c}}$ and \\ Tristan D. Yan, MD, $\mathrm{PhD}^{\mathrm{a}, \mathrm{b}}$
}

Introduction: The efficacy of coronary artery bypass graft (CABG) surgery for patients with ischemic heart disease is dependent on the patency of the selected conduit. The left internal thoracic artery is considered to be the best conduit for CABG. However, the preferred conduit between the radial artery (RA) and saphenous vein (SV) remains controversial. The present meta-analysis aims to establish the current level IA evidence on patency outcomes comparing the RA and SV.

\begin{abstract}
Methods: Electronic searches were performed using 6 databases from their inception to March 2012. Two reviewers independently identified all relevant randomized controlled trials (RCTs) comparing patency outcomes of RA and SV grafts after CABG. Data were extracted and meta-analyzed according to angiographic end points at specified follow-up intervals.

Results: Five relevant RCTs were identified for inclusion in the present meta-analysis. Angiographic results indicated that the RA was significantly more likely to be completely patent and less likely to be associated with graft failure or complete occlusion at 4 years' follow-up and beyond. However, the RA was significantly more likely to be associated with string sign at 1 year of follow-up.

Conclusions: While acknowledging the limitations of heterogeneous surgical techniques, results from the present meta-analysis suggest potential superiority of the RA compared with the SV at midterm angiographic follow-up. However, the increased incidence of string sign associated with the RA is of potential clinical concern. Further research should be directed at correlating angiographic findings of string sign and graft failure to clinical symptoms and major adverse cardiac and cerebrovascular events at long-term follow-up. (J Thorac Cardiovasc Surg 2013;146:255-61)
\end{abstract}

Coronary artery bypass graft $(\mathrm{CABG})$ surgery remains the gold standard treatment strategy for patients with left main coronary artery disease and multivessel disease. ${ }^{1,2}$ The efficacy of CABG is dependent on the long-term patency of the selected conduits. The left internal thoracic artery is established as the best conduit for CABG, particularly for grafting the left anterior descending artery. ${ }^{3}$ After initially unfavorable outcomes, ${ }^{4}$ there has been an emerging and renewed enthusiasm for the radial artery (RA) as an alternative conduit through the use of improved harvesting techniques and antispasmodic medications. ${ }^{5}$

Although a number of retrospective studies have indicated encouraging patency outcomes for $\mathrm{RAs}^{6-8}$ there

\footnotetext{
From The Systematic Review Unit, ${ }^{a}$ The Collaborative Research (CORE) Group, Sydney, Australia; The Baird Institute for Applied Heart and Lung Surgical Research, ${ }^{\mathrm{b}}$ Sydney, Australia; Department of Cardiothoracic Surgery, ${ }^{\mathrm{c}}$ St George Hospital, Sydney, Australia; and The University of Copenhagen, ${ }^{\mathrm{d}}$ Copenhagen, Denmark.

Disclosures: Authors have nothing to disclose with regard to commercial support.

Received for publication March 15, 2012; revisions received May 19, 2012; accepted for publication July 10, 2012; available ahead of print Aug 6, 2012.

Address for reprints: Tristan D. Yan, MD, PhD, The Collaborative Research (CORE)

Group, Sydney, Australia (E-mail: tristanyan@annalscts.com).

$0022-5223 / \$ 36.00$

Copyright (C) 2013 by The American Association for Thoracic Surgery

http://dx.doi.org/10.1016/j.jtcvs.2012.07.014
}

remains a lack of consistent and robust clinical data to compare the RA to the saphenous vein (SV) for patients who undergo CABG. Proponents of total arterial revascularization highlight the superior clinical and angiographic results using the $\mathrm{RA}^{9}$ whereas sceptics report poor outcomes from large retrospective studies. ${ }^{10}$ The present meta-analysis aims to provide level IA evidence for the comparison of angiographic outcomes in RA versus $\mathrm{SV}$ conduits for $\mathrm{CABG}$.

\section{PATIENTS AND METHODS}

\section{Literature Search Strategy}

Electronic searches were performed using Ovid MEDLINE, Cochrane Central Register of Controlled Trials, Cochrane Database of Systematic Reviews, ACP Journal Club, and Database of Abstracts of Review of Effectiveness from their date of inception to March 2012. Only randomized controlled trials (RCTs) were included in the present meta-analysis, as recommended by the Centre for Evidence Based Medicine guidelines to provide the highest level of clinical evidence. ${ }^{11}$ To achieve the maximum sensitivity of the search strategy and identify all studies, we combined the terms "radial artery" with "randomized controlled trial" as both keywords and MeSH headings. The reference lists of all retrieved articles were reviewed for further identification of potentially relevant studies. All relevant articles identified were assessed with application of the inclusion and exclusion criteria. $^{12}$ 


$$
\begin{aligned}
& \text { Abbreviations and Acronyms } \\
& \begin{aligned}
\text { CABG } & =\text { coronary artery bypass grafting } \\
\text { CI } & =\text { confidence interval } \\
\text { OR } & =\text { odds ratio } \\
\text { RA } & =\text { radial artery } \\
\text { RCT } & =\text { randomized controlled trial } \\
\text { SV } & =\text { saphenous vein } \\
\text { TIMI } & =\text { Thrombolysis in Myocardial Infarction }
\end{aligned}
\end{aligned}
$$

trials. $\mathrm{I}^{2}$ statistic was used to estimate the percentage of total variation across studies, owing to heterogeneity rather than chance. $\mathrm{I}^{2}$ can be calculated as: $\mathrm{I}^{2}=100 \% \times(\mathrm{Q}-d f) / \mathrm{Q}$, with $\mathrm{Q}$ defined as Cochrane's heterogeneity statistics and $d f$ defined as degree of freedom. ${ }^{15}$ An $\mathrm{I}^{2}$ value of greater than $50 \%$ was considered substantial heterogeneity. If there was substantial heterogeneity, the possible clinical and methodologic reasons for this were explored qualitatively. In the present meta-analysis the results using the random-effects model were presented to take into account the possible clinical diversity and methodologic variation between studies. Specific analyses considering confounding factors were not possible because raw data were not available. All $P$ values were 2 -sided. All statistical analysis was conducted with Review Manager Version 5.1.2 (Cochrane Collaboration, Software Update, Oxford, United Kingdom).

\section{RESULTS \\ Quantity and Quality of Trials}

A total of 512 references were identified through the 5 electronic database searches. After exclusion of duplicate or irrelevant references, 43 potentially relevant articles were retrieved. After detailed evaluation of these articles, 21 studies remained for assessment. Manual search of the reference lists did not identify any additional relevant studies. After applying the selection criteria, 5 RCTs were selected for analysis. The study characteristics of these trials are summarized in Table 1 . In these 5 studies, 1840 patients were randomized with 1708 angiographic results available for analysis to compare RA $(\mathrm{n}=859)$ versus SV (849) conduits in CABG. Surgical details and baseline characteristics are summarized in Tables 2 and 3, respectively.

The 5 RCTs were assessed qualitatively using tools designed to measure the risk of bias, as recommended by the Cochrane collaboration. A summary of selection bias, performance bias, detection bias, attrition bias, reporting bias, and other bias identified in each individual RCT is presented in Figures 1 and 2.

\section{Assessment of Complete Occlusion}

\begin{tabular}{|c|c|c|c|c|c|c|c|c|c|}
\hline First author & $\begin{array}{c}\text { Year of } \\
\text { publication }\end{array}$ & Country & Study period & $\begin{array}{l}\text { No. } \\
\text { randomized }\end{array}$ & $\begin{array}{c}\text { No. } \\
\text { analyzed }\end{array}$ & $\mathbf{R A}$ & SV & $\begin{array}{c}\text { Angiographic } \\
\text { follow-up (mo) }\end{array}$ & $\begin{array}{c}\text { Primary } \\
\text { end point }\end{array}$ \\
\hline Desai $^{16}$ & 2004 & Canada/NZ & 1996-2001 & 561 & 440 & 440 & 440 & $8-12$ & Graft occlusion \\
\hline Gaudino $^{17}$ & 2005 & Italy & 1994-1997 & 120 & 80 & 40 & 40 & 52 & Graft patency \\
\hline Collins $^{18}$ & 2008 & UK & $1998-2000$ & 147 & 103 & 59 & 44 & 67 & Graft occlusion \\
\hline Hayward $^{19}$ & 2011 & Australia & 1996-2004 & 255 & 110 & 51 & 59 & 66 & MACE \\
\hline Goldman $^{20}$ & 2011 & US & 2003-2009 & 757 & 535 & 269 & 266 & $2-24$ & Graft patency \\
\hline
\end{tabular}

Complete occlusion was not significantly different between the RA and SV at 12 months' angiographic followup $(9.1 \%$ vs $12.7 \%$; OR, $0.71 ; 95 \%$ confidence interval [CI], 0.43-1.16; $\left.P=.15 ; \mathrm{I}^{2}=51 \%\right)$. However, beyond 4 years, the RA was found to be associated with a significantly lower risk for complete occlusion $(2.7 \%$ vs $14.7 \%$; OR,

TABLE 1. Summary of study characteristics of RCTs comparing RA versus SV as conduits for CABG surgery

$R C T$, Randomized controlled trial; $R A$, radial artery; $S V$, saphenous vein; $C A B G$, coronary artery bypass grafting; $N Z$, New Zealand; $U K$, United Kingdom; $U S$, United States; $M A C E$, major adverse cardiac events, including mortality, myocardial infarction and repeat revascularisation. 
TABLE 2. Summary of surgical techniques and grafted vessels in RCTs comparing RA versus SV as conduits for CABG surgery

\begin{tabular}{lllcc}
\hline First author & Native coronary artery stenosis & Territory grafted & Elective CABG & Surgical technique \\
\hline Desai $^{16}$ & $>70 \%$ proximal lesion & RCA or LCx & $67 \%$ & NR \\
Gaudino $^{17}$ & $>70 \%$ proximal lesion; $>1 \mathrm{~mm}$ & OM1 & $100 \%$ & On pump $100 \%$ \\
Collins $^{18}$ & $>70 \%$ proximal lesion & LCx & $100 \%$ & On pump $100 \%$ \\
Hayward $^{19}$ & $>70 \%$ proximal lesion; $>1.5 \mathrm{~mm}$ & Best coronary after LAD & $71 \%$ RA, $81 \% \mathrm{SV}$ & On pump $100 \%$ \\
Goldman $^{20}$ & $>70 \%$ proximal lesion & Determined by surgeon & $100 \%$ & On pump $88 \%$ \\
\hline
\end{tabular}

$R C T$, Randomized controlled trial; $R A$, radial artery; $S V$, saphenous vein; $C A B G$, coronary artery bypass grafting; $R C A$, right coronary artery; $L C x$, left circumflex artery; $O M I$, first oblique marginal branch; $L A D$, left anterior descending artery; $N R$, not reported.

$0.17 ; 95 \% \mathrm{CI}, 0.06-0.51 ; P=.002 ; \mathrm{I}^{2}=0 \%$ ). The results beyond 4 years are summarized in Figure 3 .

\section{Assessment of String Sign}

Angiographic finding of string sign was significantly higher in the RA group than in the SV group at 12 months' follow-up (7.4\% vs $1.0 \%$; OR, 7.97; 95\% CI, 3.60-17.68; $P<.00001 ; \mathrm{I}^{2}=0 \%$ ), as well as a trend toward a higher incidence at beyond 4 years' follow-up $(2.7 \%$ vs $0 \%$; OR, $3.55 ; 95 \%$ CI, $0.57-22.11 ; P=.17 ; \mathrm{I}^{2}=0 \%$ ). The results at 1 year are summarized in Figure 4.

\section{Assessment of Graft Failure}

Graft failure from each individual RCT included patients who had RA or SV grafts that were either completely occluded or had the string sign at the time of the follow-up angiography. ${ }^{16-20}$ In addition, patients who had angiographic reports of Thrombolysis in Myocardial Infarction (TIMI) flow of 1 to $2,{ }^{16}$ those with compromised flow state of more than $50 \%,{ }^{18}$ stenosis of more than $80 \%,{ }^{19}$ or stenosis of more than $75 \%{ }^{20}$ were also categorized as having failed grafts. It is acknowledged that the angiographic end points and methodology varied among institutions. ${ }^{16-20}$ However, according to the aforementioned definitions, graft failure was similar between the RA and SV at 12 months (18.4\% vs $15.5 \%$; OR, $1.26 ; 95 \%$ CI, $0.78-2.03 ; P=.34$; $\mathrm{I}^{2}=65 \%$ ) but significantly less likely in patients who had RA beyond 4 years' follow-up $(6.0 \%$ vs $17.5 \%$; OR, $0.31 ; 95 \%$ CI, $0.14-0.68 ; P=.004 ; \mathrm{I}^{2}=0 \%$ ). These results are summarized in Figure 5.

\section{Assessment of Complete Patency}

Although complete graft patency was found to be similar between the RA and SV groups at 1 year $(79.2 \%$ vs $82.5 \%$;
OR, $0.79 ; 95 \%$ CI, $0.50-1.26 ; P=.33 ; \mathrm{I}^{2}=66 \%$ ), the RA was more likely to result in a completely patent graft than was the SV beyond 4 years $(89.9 \%$ vs $63.1 \%$; OR, 5.19 ; 95\% CI, 2.35-11.47; $P<.0001 ; \mathrm{I}^{2}=0 \%$ ). The results beyond 4 years are summarized in Figure 6.

\section{DISCUSSION}

Carpentier and associates ${ }^{4}$ first described the use of the RA in aorta-to-coronary artery bypass grafting in 1973 by reporting the short-term outcomes of 40 grafts in 30 patients. The advantages of the RA compared with the SV were duly noted, including the arterial structure, elasticity, and regularity of the lumen. However, the RA as an alternative conduit was largely abandoned for decades owing to concerns about spasm, early occlusion, and competitive flow. Since then, an improved understanding of the natural history of histologic changes in venous and arterial grafts and pharmacologic implications of antispasmodic drugs has culminated in a revival of the RA in the 1990s. ${ }^{5,21,22}$ In addition, revelation of the significant attrition rate of the SV conduit has further encouraged the exploration of arterial conduits. ${ }^{23}$ Despite enthusiasm for total arterial revascularization from some centers, uncertainty regarding the superiority of the RA compared with the SV used in conventional CABG has prevented the widespread acceptance of the RA as a preferred conduit. ${ }^{10,24,25}$ A lack of consensus among clinicians is partly reflected by the fluctuating use of the RA for isolated CABG from $12.3 \%$ in 2002 to $5.5 \%$ in 2009 according to The Society of Thoracic Surgeons database. ${ }^{26}$

Benedetto and associates ${ }^{27}$ performed a meta-analysis of RCTs from 4 centers comparing the RA and SV using graft failure as the sole end point. This study did not include a recent RCT involving the largest number of participants to

TABLE 3. Summary of patient baseline characteristics of RCTs comparing RA versus SV as conduits for CABG surgery

\begin{tabular}{|c|c|c|c|c|c|c|c|c|c|c|c|c|}
\hline \multirow[b]{2}{*}{ Study } & \multicolumn{2}{|c|}{ Age (y) } & \multicolumn{2}{|c|}{ Female } & \multicolumn{2}{|c|}{ Diabetes mellitus } & \multicolumn{2}{|c|}{ Hypertension } & \multicolumn{2}{|c|}{ Current smoker } & \multicolumn{2}{|c|}{ Previous MI } \\
\hline & RA & SV & RA & SV & RA & SV & RA & SV & RA & SV & RA & SV \\
\hline $\begin{array}{l}\text { Desai }^{16} \\
\text { Gaudino }^{17 *}\end{array}$ & 61 & & $57 \%$ & & $26 \%$ & & $46 \%$ & & $17 \%$ & & $46 \%$ & \\
\hline Collins $^{18}$ & 58 & 58 & $3 \%$ & $5 \%$ & $19 \%$ & $14 \%$ & $58 \%$ & $50 \%$ & $17 \%$ & $5 \%$ & $51 \%$ & $45 \%$ \\
\hline Hayward $^{19}$ & 73 & 73 & $20 \%$ & $14 \%$ & $29 \%$ & $39 \%$ & $47 \%$ & $61 \%$ & $73 \% \dagger$ & $71 \% \dagger$ & NR & NR \\
\hline Goldman $^{20}$ & 61 & 62 & $1 \%$ & $1 \%$ & $42 \%$ & $42 \%$ & $79 \%$ & $79 \%$ & $23 \%$ & $27 \%$ & $40 \%$ & $39 \%$ \\
\hline
\end{tabular}

$R C T$, Randomized controlled trial; $R A$, radial artery; $S V$, saphenous vein; $C A B G$, coronary artery bypass grafting; $M I$, myocardial infarction. * No specific data available for RA and SV groups. †Ever smokers. 


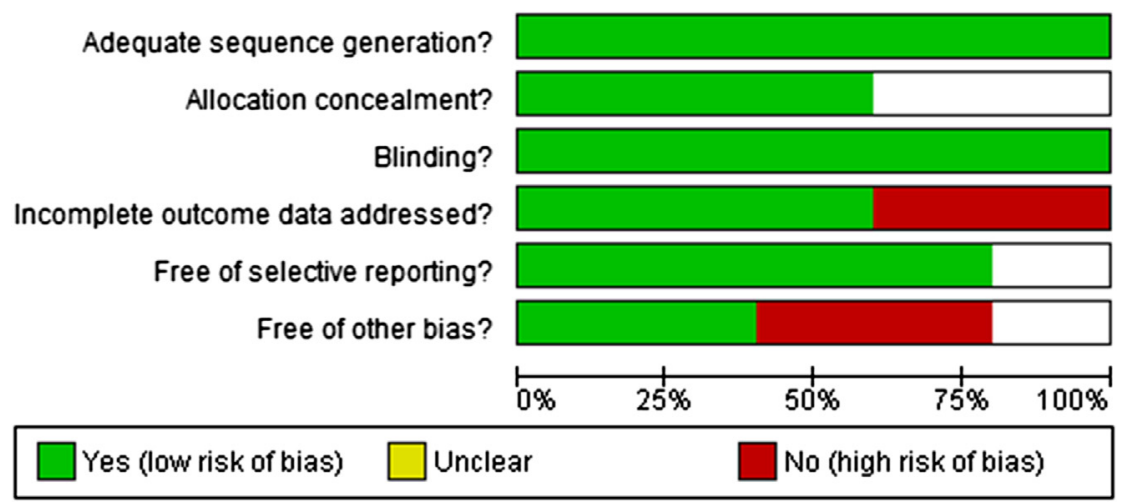

FIGURE 1. Methodologic quality graph summarizing the risk of bias from randomized controlled trials comparing radial artery versus saphenous vein for coronary artery bypass graft surgery.

date, ${ }^{20}$ and it did not stratify patency outcomes according to different follow-up intervals. The authors concluded that the RA and SV had similar graft failure rates but were criticized for their methodology. ${ }^{28}$ More recently, Athanasiou and associates performed a thorough systematic review

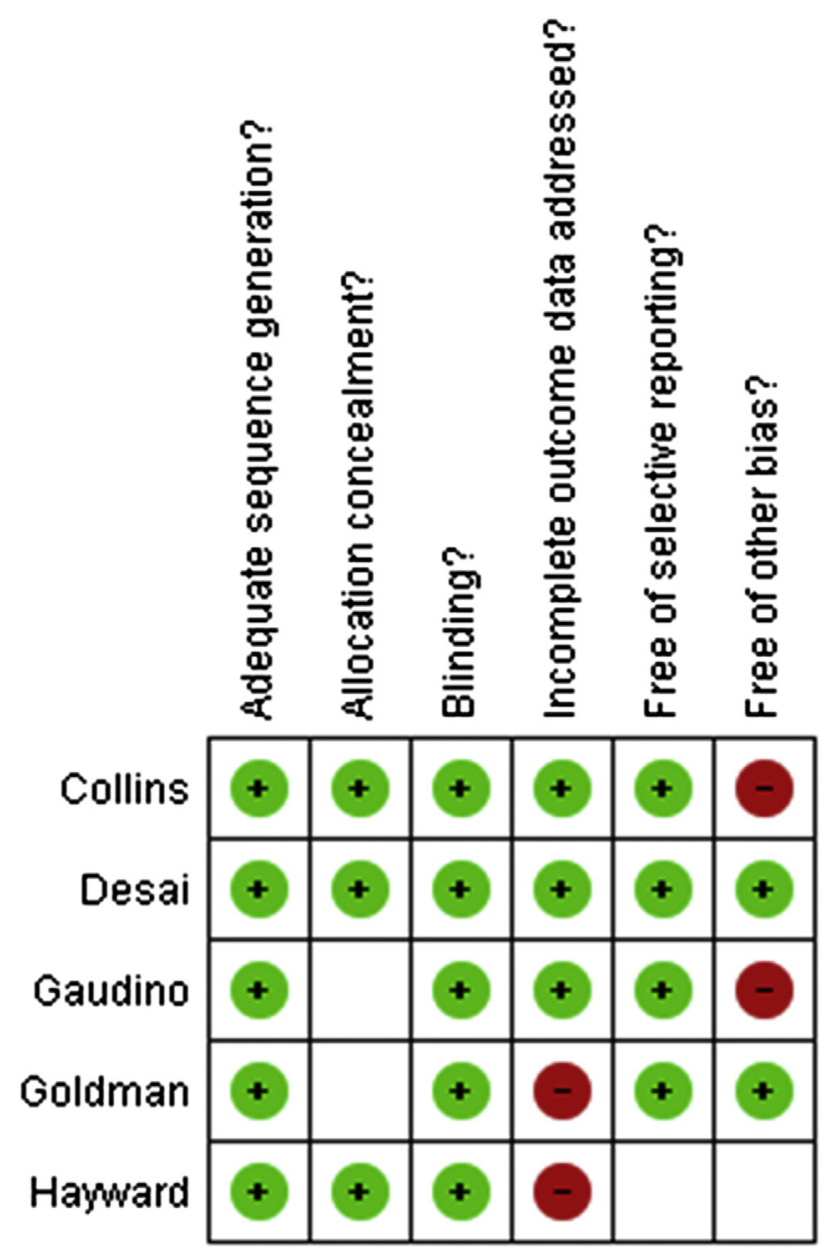

FIGURE 2. Methodological quality summary of randomized controlled trials comparing radial artery versus saphenous vein for coronary artery bypass graft surgery. and meta-analysis of all randomized and nonrandomized studies comparing the RA and SV, citing the inadequacy of including only RCTs. This meta-analysis grouped RCTs with retrospective observational studies, some of which had controversial study designs and outcomes. ${ }^{10,29}$ The present meta-analysis aimed to assess the level IA clinical evidence of the RA versus the SV using multiple angiographic patency end points at specified time intervals according to recommended guidelines. ${ }^{11}$

Results of the present meta-analysis indicate that the RA does not appear to be superior to the SV at 1 year of followup, and indeed it is more likely to be associated with the string sign, which is generally considered to be a form of graft failure. ${ }^{30-32}$ However, the RA has significantly superior angiographic patency outcomes compared with the SV at 4 years and beyond, according to end points of complete graft occlusion, graft failure, and complete patency. Heterogeneity assessment of these long-term studies revealed a low degree of heterogeneity $\left(\mathrm{I}^{2}=0 \%\right)$ in all measured outcomes. Overall, our findings are consistent with previous observational studies that report superior outcomes from total arterial revascularization compared with conventional $\mathrm{CABG}$ using venous conduits, which becomes more evident on longer follow-up. ${ }^{23}$

The significance of the angiographic string sign has long been recognized, not only in conduits used in CABG but for other systemic vascular diseases. ${ }^{33}$ Miwa and associates. ${ }^{34}$ retrospectively analyzed their data from the Radial Artery Patency Study (RAPS) trial, ${ }^{16}$ which identified string sign in 31 of $440 \mathrm{RA}$ and 4 of $440 \mathrm{SV}$ grafts $(P=.001)$. In their study, string sign was defined a priori as a patent graft that was diffusely narrowed, with a diameter less than $1 \mathrm{~mm}$. It was further categorized as "complete" if the narrowing was along the full length of the graft or "partial" if only a segment was affected. Although the results of this study clearly demonstrated a preponderance for string signs in RA grafts, especially in patients with less than $90 \%$ narrowing of the native coronary artery, the clinical impact of this angiographic phenomenon was less clear. Clinical findings of 


\begin{tabular}{|c|c|c|c|c|c|c|c|c|c|}
\hline Study or Subgroup & $\begin{array}{r}\text { RA } \\
\text { Events }\end{array}$ & Total & $\begin{array}{r}\text { SV } \\
\text { Events }\end{array}$ & Total & Weight & $\begin{array}{c}\text { Odds Ratio } \\
\text { M- } \mathrm{H}, \text { Random, } 95 \% \mathrm{Cl}\end{array}$ & $\begin{array}{r}\text { Odds } \mathrm{F} \\
\text { M-H, Rando }\end{array}$ & $\begin{array}{l}\text { Ratio } \\
\text { om, } 95 \% \mathrm{Cl}\end{array}$ & \\
\hline Collins & 1 & 59 & 6 & 44 & $26.1 \%$ & $0.11[0.01,0.94]$ & & & \\
\hline Gaudino & 1 & 40 & 7 & 40 & $26.4 \%$ & $0.12[0.01,1.03]$ & & & \\
\hline Hawward & 2 & 51 & 8 & 59 & $47.5 \%$ & $0.26[0.05,1.29]$ & & & \\
\hline Total $(95 \% \mathrm{Cl})$ & & 150 & & 143 & $100.0 \%$ & $0.17[0.06,0.51]$ & & & \\
\hline \multirow{2}{*}{\multicolumn{7}{|c|}{$\begin{array}{l}\text { Heterogeneity: } \mathrm{Tau}^{2}=0.00 ; \mathrm{Chi}^{2}=0.53, \mathrm{df}=2(P=0.77) ;\left.\right|^{2}=0 \% \\
\text { Test for overall effect: } Z=3.16(P=0.002)\end{array}$}} & & & \\
\hline & & & & & & & $\begin{array}{cc}0.001 & 0.1 \\
\text { Complete occlusions Sv }\end{array}$ & $\begin{array}{r}10 \\
\text { Complete }\end{array}$ & $\begin{array}{l}1000 \\
\text { ns RA }\end{array}$ \\
\hline
\end{tabular}

FIGURE 3. Forest plot of the odds ratio $(O R)$ of complete occlusion beyond 4 years after using radial artery $(R A)$ versus saphenous vein $(S V)$ as a conduit during coronary artery bypass grafting. The estimate of the OR of each trial corresponds to the middle of the squares, and the horizontal line shows the $95 \%$ confidence interval $(C I)$. On each line, the number of events as a fraction of the total number randomized is shown for both treatment groups. For each subgroup, the sum of the statistics, along with the summary OR, is represented by the middle of the solid diamonds. A test of heterogeneity between the trials within a subgroup is given below the summary statistics. $M$ - $H$, Mantel-Haenszel.

angina appeared to correlate more with TIMI flow rather than the string sign itself. Furthermore, there was no significant difference in the incidence of myocardial infarction between patients who had string signs compared with those who did not, although the authors acknowledged limitations owing to their relatively small sample size. Certainly, the nonlinear correlation between TIMI flow and the incidence of string sign suggests the cause may be multifactorial, such as competitive collateral flow, translesional flow through a small target artery, poor harvesting technique, or inherent graft disease. ${ }^{30,31}$ Nonetheless, results from the present study warrant further prospective studies that examine the correlation of the string sign from RA conduits to potentially significant clinical end points.

A number of limitations should be acknowledged about the present study, and the results should be interpreted with caution. First, patients from the RCTs included in the present meta-analysis are a highly selected cohort who underwent isolated CABG. Specifically, all patients had to have a greater than $70 \%$ proximal lesion in the native coronary vessel, inasmuch as it has been established that patients with lower-grade lesions had an increased propensity for competitive flow and were probably not suitable or ethical for randomization. ${ }^{16-20}$ Second, graft patency is dependent on a number of important variables. These include the type of conduit used, size of the native coronary artery, the severity and location of disease, the territory of the runoff, the surgical technique and experience of the surgeon, and perioperative use of antispasmodic medications, all of which differed among studies. This may partly explain the heterogeneity identified between the 2 large RCTs conducted by Desai, ${ }^{16}$ Goldman, ${ }^{20}$ and their associates, the latter of which included a significant proportion of patients who underwent off-pump CABG. However, owing to the randomization process, confounding factors were minimized within each individual study, and the present meta-analysis represents a summary of the highest level of evidence in the current literature.

In view of our findings, we conclude that the RA offers better midterm angiographic patency outcomes than does the SV for selected patients with severe proximal lesions in the setting of multivessel disease. However, their likelihood of causing the string sign and the lack of clear evidence on clinical end points such as major adverse cerebrovascular and cardiac events warrants further randomized studies with longer follow-up and measurement of clinical outcomes. Future trials should also assess

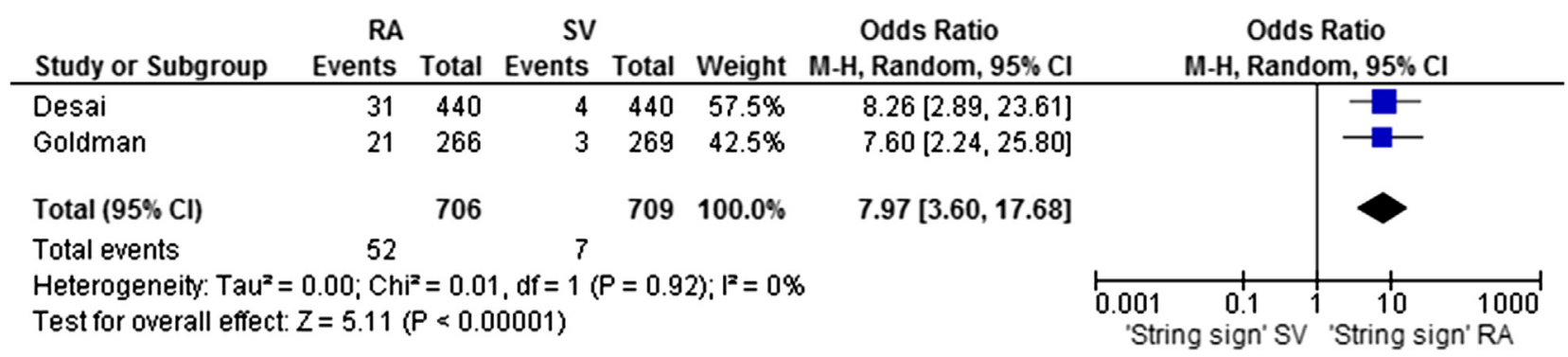

FIGURE 4. Forest plot of the odds ratio $(O R)$ of string sign angiographic finding at 1 year after using radial artery $(R A)$ versus saphenous vein ( $S V)$ as a conduit during coronary artery bypass grafting. The estimate of the OR of each trial corresponds to the middle of the squares, and the horizontal line shows the $95 \%$ confidence interval $(C I)$. On each line, the number of events as a fraction of the total number randomized is shown for both treatment groups. For each subgroup, the sum of the statistics, along with the summary $\mathrm{OR}$, is represented by the middle of the solid diamonds. A test of heterogeneity between the trials within a subgroup is given below the summary statistics. $M-H$, Mantel-Haenszel. 


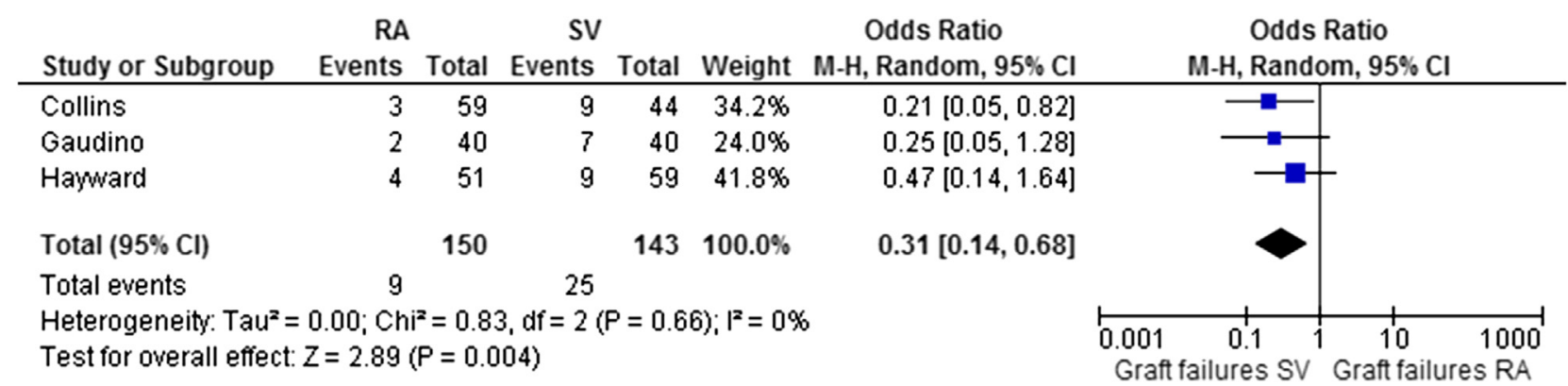

FIGURE 5. Forest plot of the odds ratio $(O R)$ of graft failure beyond 4 years after using radial artery $(R A)$ versus saphenous vein $(S V)$ as a conduit during coronary artery bypass grafting. The estimate of the OR of each trial corresponds to the middle of the squares, and the horizontal line shows the $95 \%$ confidence interval $(\mathrm{CI})$. On each line, the number of events as a fraction of the total number randomized is shown for both treatment groups. For each subgroup, the sum of the statistics, along with the summary OR, is represented by the middle of the solid diamonds. A test of heterogeneity between the trials within a subgroup is given below the summary statistics. $M-H$, Mantel-Haenszel.

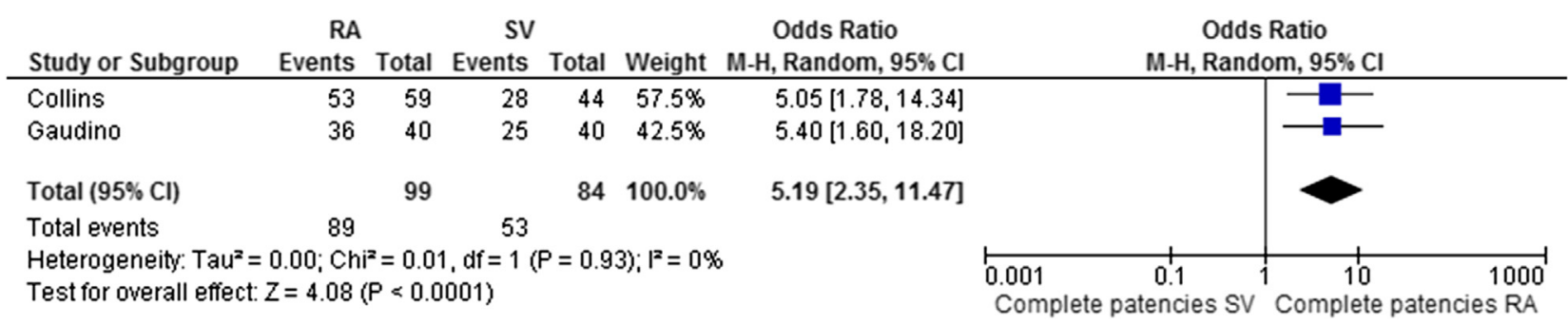

FIGURE 6. Forest plot of the odds ratio $(O R)$ of complete patency beyond 4 years after using radial artery $(R A)$ versus saphenous vein $(S V)$ as a conduit during coronary artery bypass grafting. The estimate of the OR of each trial corresponds to the middle of the squares, and the horizontal line shows the $95 \%$ confidence interval $(C I)$. On each line, the number of events as a fraction of the total number randomized is shown for both treatment groups. For each subgroup, the sum of the statistics, along with the summary OR, is represented by the middle of the solid diamonds. A test of heterogeneity between the trials within a subgroup is given below the summary statistics. $M-H$, Mantel-Haenszel.

potential differences in costs and quality of life that are not apparent on short-term follow-up. ${ }^{35}$

We thank Dr Karthik Ramakrishnan and Ms. Victoria Hardie for their generous assistance with this manuscript.

\section{References}

1. Serruys PW, Morice MC, Kappetein AP, Colombo A, Holmes DR, Mack MJ, et al. Percutaneous coronary intervention versus coronary-artery bypass grafting for severe coronary artery disease. New Engl J Med. 2009;360:961-72.

2. Cao C, Manganas C, Bannon P, Vallely M, Yan TD. Drug-eluting stents versus coronary artery bypass graft surgery in left main coronary artery disease: a meta-analysis of early outcomes from randomized and nonrandomized studies. J Thorac Cardiovasc Surg. 2012 Mar 9 [Epub ahead of print.]

3. Cameron AA, Green GE, Brogno DA, Thornton J. Internal thoracic artery grafts: 20-year clinical follow-up. J Am Coll Cardiol. 1995;25:188-92.

4. Carpentier A, Guermonprez JL, Deloche A, Frechette C, DuBost C. The aorta-tocoronary radial artery bypass graft. A technique avoiding pathological changes in grafts. Ann Thorac Surg. 1973;16:111-21.

5. Acar C, Jebara VA, Portoghese M, Beyssen B, Pagny JY, Grare P, et al. Revival of the radial artery for coronary artery bypass grafting. Ann Thorac Surg. 1992;54: 652-9; discussion 659-60.

6. Possati G, Gaudino M, Prati F, Alessandrini F, Trani C, Glieca F, et al. Long-term results of the radial artery used for myocardial revascularization. Circulation. 2003;108:1350-4.

7. Yie K, Na C-Y, Oh SS, Kim J-H, Shinn S-H, Seo H-J. Angiographic results of the radial artery graft patency according to the degree of native coronary stenosis. Eur J Cardiothorac Surg. 2008;33:341-8.

8. Ikeda M, Ohashi H, Tsutsumi Y, Hige K, Kawai T, Ohnaka M. Angiographic evaluation of the luminal changes in the radial artery graft in coronary artery by- pass surgery: a concern over the long-term patency. Eur J Cardiothorac Surg. 2002;21:800-3.

9. Muneretto C, Bisleri G, Negri A, Manfredi J, Metra M, Nodari S, et al. Total arterial myocardial revascularization with composite grafts improves results of coronary surgery in elderly: a prospective randomized comparison with conventional coronary artery bypass surgery. Circulation. 2003;108(Suppl 1):II29-33.

10. Khot UN, Friedman DT, Pettersson G, Smedira NG, Li J, Ellis SG. Radial artery bypass grafts have an increased occurrence of angiographically severe stenosis and occlusion compared with left internal mammary arteries and saphenous vein grafts. Circulation. 2004;109:2086-91.

11. Centre for Evidence Based Medicine-Levels Of Evidence (March 2009). Oxford University. Available at: http://www.cebm.net/index.aspx?o=1025. Accessed March 1, 2012.

12. Moher D, Liberati A, Tetzlaff J, Altman DG, Group P. Preferred reporting items for systematic reviews and meta-analyses: the PRISMA statement. J Clin Epidemiol. 2009;62:1006-12.

13. Higgins JPT, Green S, eds. Cochrane handbook for systematic reviews of interventions version 5.1.0. The Cochrane Collaboration; March 2011.

14. DerSimonian R, Laird N. Meta-analysis in clinical trials. Control Clin Trials. 1986;7:177-88

15. Higgins JP, Thompson SG. Quantifying heterogeneity in a meta-analysis. Stat Med. 2002;21:1539-58.

16. Desai ND, Cohen EA, Naylor CD, Fremes SE, Radial Artery Patency Study I. A randomized comparison of radial-artery and saphenous-vein coronary bypass grafts. N Engl J Med. 2004;351:2302-9.

17. Gaudino M, Cellini C, Pragliola C, Trani C, Burzotta F, Schiavoni G, et al. Arterial versus venous bypass grafts in patients with in-stent restenosis. Circulation. 2005;112(9 Suppl):I265-9.

18. Collins P, Webb CM, Chong CF, Moat NE, Radial Artery Versus Saphenous Vein Patency Trial I. Radial artery versus saphenous vein patency randomized trial: five-year angiographic follow-up. Circulation. 2008;117:2859-64. 
19. Hayward PAR, Buxton BF. The Radial Artery Patency and Clinical Outcomes trial: design, intermediate term results and future direction. Heart Lung Circ. 2011;20:187-92.

20. Goldman S, Sethi GK, Holman W, Thai H, McFalls E, Ward HB, et al. Radial artery grafts vs saphenous vein grafts in coronary artery bypass surgery: a randomized trial. JAMA. 2011;305:167-74

21. Hagiwara H, Ito T, Kamiya H, Akita T, Usui A, Ueda Y. Mid-term structural change in the radial artery grafts after coronary artery bypass grafting. Ann Thorac Surg. 2004;77:805-10; discussion 810-11.

22. Webb CM, Moat NE, Chong CF, Collins P. Vascular reactivity and flow characteristics of radial artery and long saphenous vein coronary bypass grafts: a 5-year follow-up. Circulation. 2010;122:861-7.

23. Zacharias A, Schwann TA, Riordan CJ, Durham SJ, Shah AS, Habib RH. Late results of conventional versus all-arterial revascularization based on internal thoracic and radial artery grafting. Ann Thorac Surg. 2009;87:19-26.e12.

24. Taggart DP. The radial artery as a conduit for coronary artery bypass grafting. Heart. 1999;82:409-10

25. Taggart DP, D'Amico R, Altman DG. Effect of arterial revascularisation on survival: a systematic review of studies comparing bilateral and single internal mammary arteries. Lancet. 2001;358:870-5.

26. ElBardissi AW, Aranki SF, Sheng S, O'Brien SM, Greenberg CC, Gammie JS. Trends in isolated coronary artery bypass grafting: an analysis of the Society of Thoracic Surgeons adult cardiac surgery database. J Thorac Cardiovasc Surg. 2012;143:273-81.

27. Benedetto U, Angeloni E, Refice S, Sinatra R. Radial artery versus saphenous vein graft patency: meta-analysis of randomized controlled trials. J Thorac Cardiovasc Surg. 2010;139:229-31.
28. Athanasiou T, Rao C, Buxton BF. Meta-analysis covers the horizon when the literature search is undertaken through a keyhole. J Thorac Cardiovasc Surg. 2010; 139:1669-70; author reply 1670-1.

29. Acar C, Cook RC, Letter regarding article by Khot UN, Friedman DT, Pettersson G, Smedira NG, Li J, Ellis SG. "Radial artery bypass grafts have an increased occurrence of angiographically severe stenosis and occlusion compared with left internal mammary arteries and saphenous vein grafts." Circulation. 2005;111:e6-9; author reply e6-9.

30. Nezic D, Knezevic A, Cirkovic M. Are we allowed to declare radial artery graft with a "string sign" for a patent conduit? Eur J Cardiothorac Surg. 2009;36: 605-6; author reply 606-7.

31. Royse AG, Royse CF, Tatoulis J, Grigg LE, Shah P, Hunt D, et al. Postoperative radial artery angiography for coronary artery bypass surgery. Eur J Cardiothorac Surg. 2000;17:294-304.

32. Buxton BF, Raman JS, Ruengsakulrach P, Gordon I, Rosalion A, Bellomo R, et al. Radial artery patency and clinical outcomes: five-year interim results of a randomized trial. J Thorac Cardiovasc Surg. 2003;125:1363-71.

33. Spacek M, Martinkovicova L, Zimolova P, Veselka J. Mid-term outcomes of carotid artery stenting in patients with angiographic string sign. Catheter Cardiovasc Interv. 2012;79:174-9.

34. Miwa S, Desai N, Koyama T, Chan E, Cohen EA, Fremes SE, Radial Artery Patency Study I. Radial artery angiographic string sign: clinical consequences and the role of pharmacologic therapy. Ann Thorac Surg. 2006;81:112-8; discussion 119.

35. Wagner TH, Sethi G, Holman W, Lee K, Bakaeen FG, Upadhyay A, et al. Costs and quality of life associated with radial artery and saphenous vein cardiac bypass surgery: results from a Veterans Affairs multisite trial. Am J Surg. 2011; 202:532-5. 